\title{
Relative Energy and Structural Differences of Axial and
}

\section{Equatorial 1-Fluoro-1-Silacyclohexane}

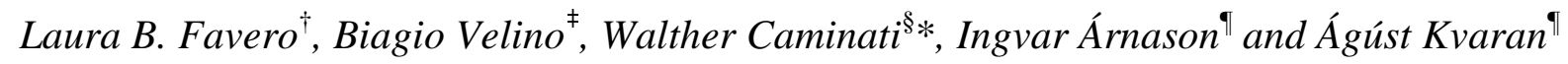

${ }^{\dagger}$ Istituto per lo Studio dei Materiali Nanostrutturati (ISMN, Sezione di Bologna), CNR, Via Gobetti 101, I-40129 Bologna, Italy.

${ }^{\ddagger}$ Dipartimento di Chimica Fisica e Inorganica dell'Università, Viale Risorgimento 4, I-40136 Bologna, Italy

${ }^{\S}$ Dipartimento di Chimica "G.Ciamician" dell'Università, Via Selmi 2, I-40126 Bologna, Italy.

${ }^{7 / S c i e n c e ~ I n s t i t u t e, ~ U n i v e r s i t y ~ o f ~ I c e l a n d, ~ D u n h a g a ~ 3, ~} 107$ Reykjavík, Iceland.

*walther.caminati@unibo.it

Supporting Information Available: 2 Tables of rotational transition frequencies. 
Table S1. Standing cell transition frequencies (MHz) of normal FSCH.

\begin{tabular}{|c|c|c|c|c|c|}
\hline \multirow[b]{2}{*}{$J^{\prime}\left(K_{\mathrm{a}}{ }^{\prime}, K_{\mathrm{c}}{ }^{\prime}\right) \leftarrow J^{\prime}\left(K_{\mathrm{a}}{ }^{\prime}, K_{\mathrm{c}}{ }^{\prime \prime}\right)$} & \multicolumn{2}{|c|}{ Axial } & \multicolumn{3}{|c|}{ Equatorial } \\
\hline & g.s. & $\mathrm{V}=1$ & g.s. & $v_{1}=1$ & $\mathrm{v}_{2}=1$ \\
\hline $8(6,3)-7(6,2)$ & 27922.28 & 27886.48 & & & \\
\hline $8(6,2)-7(6,1)$ & 27924.72 & & & & \\
\hline $9(0,9)-8(0,8)$ & 27844.20 & & & & \\
\hline $9(1,9)-8(1,8)$ & 27841.00 & & & & \\
\hline $9(1,8)-8(1,7)$ & 29514.92 & & & & \\
\hline $9(2,8)-8(2,7)$ & 29424.47 & & & & \\
\hline $9(2,7)-8(2,6)$ & 31479.57 & & & & \\
\hline $9(3,6)-8(3,5)$ & 32838.65 & & & & \\
\hline $9(4,5)-8(4,4)$ & 32539.78 & & & & \\
\hline $9(6,4)-8(6,3)$ & 31492.70 & & & & \\
\hline $9(6,3)-8(6,2)$ & 31503.70 & 31463.40 & & & \\
\hline $10(0,10)-9(0,9)$ & 30846.00 & 30794.99 & & & \\
\hline $10(1,10)-9(1,9)$ & 30845.58 & & & & \\
\hline $10(1,9)-9(1,8)$ & 32486.71 & 32440.47 & & 28628.70 & \\
\hline $10(2,9)-9(2,8)$ & 32447.21 & & 28359.66 & & \\
\hline $10(2,8)-9(2,7)$ & 34370.68 & 34331.21 & 30992.34 & & \\
\hline $10(3,8)-9(3,7)$ & 33927.63 & 33884.49 & 29800.40 & 29822.23 & 29785.40 \\
\hline $10(3,7)-9(3,6)$ & 36212.02 & 36174.72 & 31901.86 & 31933.92 & 31892.93 \\
\hline $10(4,7)-9(4,6)$ & 34911.29 & 34868.73 & 30389.58 & 30418.88 & 30376.90 \\
\hline $10(4,6)-9(4,5)$ & 36477.03 & & 31087.71 & 31130.70 & 31078.26 \\
\hline $10(5,6)-9(5,5)$ & 35189.51 & 35145.74 & 30379.46 & 30411.70 & \\
\hline $10(5,5)-9(5,4)$ & 35593.87 & 35548.55 & 30455.02 & 30489.70 & \\
\hline $10(6,5)-9(6,4)$ & 35087.00 & & 30253.65 & 30285.50 & \\
\hline $10(6,4)-9(6,3)$ & 35125.40 & & 30257.60 & 30289.65 & \\
\hline $10(7,4)-9(7,3)$ & 34951.40 & 34907.17 & & & \\
\hline $10(7,3)-9(7,2)$ & 34953.60 & 34909.03 & & & \\
\hline $11(0,11)-10(0,10)$ & & & 29016.50 & 29041.80 & 28991.70 \\
\hline $11(1,11)-10(1,10)$ & & & 29010.94 & 29036.20 & 28986.24 \\
\hline $11(1,10)-10(1,9)$ & 35474.64 & & 31099.42 & 31115.08 & 31078.27 \\
\hline $11(2,10)-10(2,9)$ & 35458.16 & 35405.98 & 30952.88 & 30972.92 & 30931.76 \\
\hline $11(2,9)-10(2,8)$ & 37257.00 & 37211.48 & 33555.76 & 33562.35 & 33538.75 \\
\hline $11(3,9)-10(3,8)$ & 37014.68 & 36966.80 & 32574.98 & 32596.84 & 32557.80 \\
\hline $11(3,8)-10(3,7)$ & 39333.68 & 39293.52 & & 35103.34 & 35064.40 \\
\hline $11(4,8)-10(4,7)$ & 38222.32 & & 33404.80 & 33434.90 & 33390.37 \\
\hline $11(4,7)-10(4,6)$ & & & 34561.82 & 34610.31 & 34552.38 \\
\hline $11(5,7)-10(5,6)$ & 38733.01 & & 33495.78 & & 33482.25 \\
\hline $11(5,6)-10(5,5)$ & 39546.40 & & 33672.80 & 33713.90 & 33660.32 \\
\hline $11(6,6)-10(6,5)$ & 38699.60 & 38650.88 & 33354.70 & & 33340.90 \\
\hline $11(6,5)-10(6,4)$ & 38811.74 & 38762.42 & 33366.60 & 33402.80 & \\
\hline $11(7,5)-10(7,4)$ & 38537.40 & 38488.60 & & & \\
\hline $11(7,4)-10(7,3)$ & 38545.00 & & & & \\
\hline $11(8)-10(8)^{\mathrm{a}}$ & 38413.10 & & 33159.52 & & \\
\hline $11(9)-10(2)^{\mathrm{a}}$ & 38328.40 & 38279.52 & 33107.44 & & \\
\hline $11(10)-10(10)^{\mathrm{a}}$ & 38269.06 & 38220.08 & 33070.30 & & \\
\hline $12(0,12)-11(0,11)$ & & & 31561.82 & 31589.67 & 31534.62 \\
\hline $12(1,12)-11(1,11)$ & & & 31559.36 & 31587.34 & 31532.12 \\
\hline $12(1,11)-11(1,10)$ & 38470.60 & & 33604.67 & 33623.96 & 33581.00 \\
\hline $12(2,11)-11(2,10)$ & 38463.80 & 38406.30 & 33525.69 & 33547.60 & \\
\hline $12(2,10)-11(2,9)$ & & & 36009.18 & 36015.14 & \\
\hline $12(3,10)-11(3,9)$ & & & 35288.50 & 35310.28 & 35268.86 \\
\hline $12(3,9)-11(3,8)$ & & & 38072.45 & 38094.24 & 38059.00 \\
\hline $12(4,9)-11(4,8)$ & & & 36366.42 & 36396.60 & 36350.25 \\
\hline $12(4,8)-11(4,7)$ & & & 38057.46 & 38108.02 & 38047.62 \\
\hline $12(5,8)-11(5,7)$ & & & & 36648.53 & \\
\hline $12(5,7)-11(5,6)$ & & & 36979.08 & 37028.00 & \\
\hline $12(6,7)-11(6,6)$ & & & 36474.70 & & 36459.90 \\
\hline $12(6,6)-11(6,5)$ & & & 36507.40 & 36548.00 & 36492.85 \\
\hline $12(8)-11(8)^{\mathrm{a}}$ & & & 36225.11 & & \\
\hline $12(9)-11(9)^{\mathrm{a}}$ & & & 36157.04 & & \\
\hline $12(10)-11(10)^{\mathrm{a}}$ & & & 36108.97 & & \\
\hline $12(11)-11(11)^{\mathrm{a}}$ & & & 36073.55 & & \\
\hline $13(0,13)-12(0,12)$ & & & 34108.04 & 34138.58 & 34078.38 \\
\hline $13(1,13)-12(1,12)$ & & & 34107.04 & 34137.58 & 34077.32 \\
\hline $13(1,12)-12(1,11)$ & & & 36126.78 & & 36100.58 \\
\hline $13(2,12)-12(2,11)$ & & & 36085.80 & 36110.01 & 36059.98 \\
\hline $13(2,11)-12(2,10)$ & & & 38427.15 & 38435.55 & 38404.52 \\
\hline $13(3,11)-12(3,10)$ & & & 37949.06 & 37971.04 & \\
\hline $13(4,10)-12(4,9)$ & & & 39263.94 & 39293.53 & \\
\hline $13(5,9)-12(5,8)$ & & & & 39748.14 & \\
\hline $13(6,8)-12(6,7)$ & & & 39611.27 & 39654.60 & \\
\hline $13(6,7)-12(6,6)$ & & & & 39737.15 & \\
\hline $13(7,7)-12(7,6)$ & & & 39433.01 & & 39416.83 \\
\hline $13(7,6)-12(7,5)$ & & & 39437.90 & 39480.60 & \\
\hline $13(9)-12(9)^{\mathrm{a}}$ & & & 39217.35 & 39257.75 & \\
\hline $13(10)-12(10)^{\mathrm{a}}$ & & & 39155.90 & 39195.72 & \\
\hline $13(11)-12(11)^{\mathrm{a}}$ & & & 39110.90 & 39150.21 & \\
\hline $14(1,13)-13(1,12)$ & & & 38659.46 & & 38630.96 \\
\hline $14(2,13)-13(2,12)$ & & & 38638.92 & 38665.49 & 38610.48 \\
\hline
\end{tabular}

\footnotetext{
${ }^{\mathrm{a}}$ Doubly overlapped transition, due to the near oblate degeneracy of the involved levels, only $K_{\mathrm{a}}$ is given.
} 


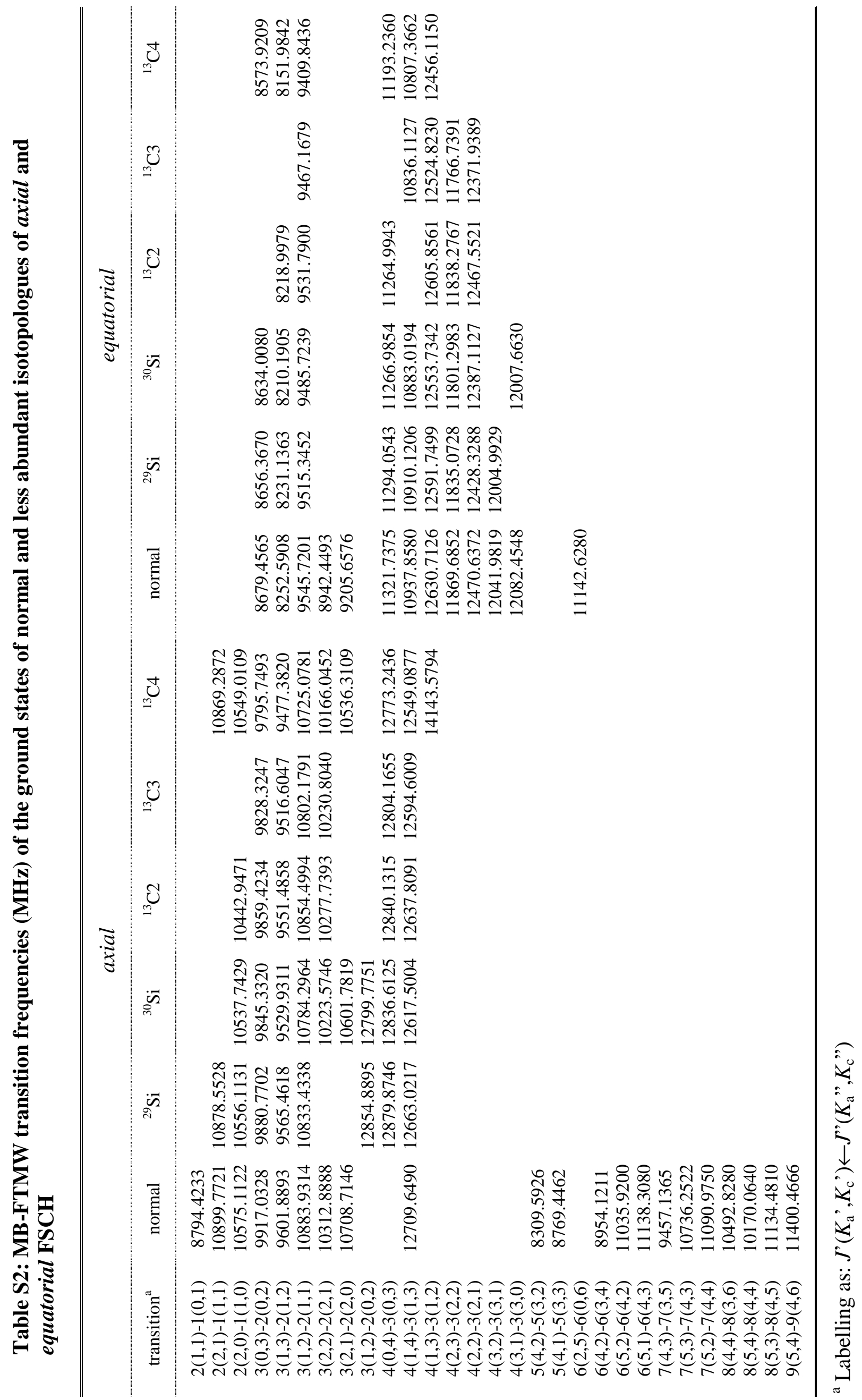

